\title{
The penetration of the Northern Current over the Gulf of Lions (Mediterranean) as a downscaling problem
}

\author{
Francis AUCLAIR*, Patrick MARSALEIX, Claude ESTOURNEL \\ Laboratoire d'aérologie, UMR CNRS/UPS 5560, Observatoire Midi-Pyrénées, 14, avenue E.-Belin, \\ 31400 Toulouse, France
}

Received 25 October 2000; revised 13 July 2001; accepted 16 July 2001

\begin{abstract}
Coastal shelf models suffer from the difficulty of specifying both the initial field and the external circulation at the open boundary. Only basin scale models can have the right space-time variability to routinely provide such information. De facto, such models have however a coarser resolution than the coastal model and the downscaling of the circulation to the high resolution grid is biased. Indeed the models are not necessarily based on the same physics and the interactions of the general circulation with the topography, in particular over the shelf break region, are generally not correctly represented on the large-scale grid. Studying the response of the Northern Current to the atmospheric forcing in the region of Marseille (France) and its interactions with the continental shelf break, we evaluate in this paper the spurious consequences at short and medium range that can result from a crude interpolation of basin scale model outputs to initialize and force along its open boundaries a high resolution coastal model. We show how an analysis of these fields based on a 3D variational initialization technique can improve the results. (C) 2001 Ifremer/CNRS/IRD/Éditions scientifiques et médicales Elsevier SAS
\end{abstract}

Résumé - La pénétration du Courant Nord dans le golfe du Lion (Méditerranée) et le problème de réduction d'échelle. L'initialisation et la spécification des conditions aux limites ouvertes sont deux difficultés récurrentes ayant trait à la modélisation de l'océan côtier. Seuls les modèles de bassin possèdent la variabilité spatio-temporelle indispensable pour fournir de façon routinière de telles informations. Ces modèles de bassin ayant de fait une résolution plus faible que le modèle côtier, les informations sur la circulation générale qu'ils fournissent sont biaisées. En effet les modèles côtiers et les modèles de bassin ne sont pas nécessairement basés sur la même dynamique et les interactions de la circulation générale avec la topographie, en particulier le long du talus continental, ne sont pas correctement modélisées dans les modèles de grande échelle. À partir de l'étude de la réponse du Courant Nord méditerranéen aux forçages atmosphériques dans la région de Marseille (France) et de son interaction avec le talus continental, nous évaluons dans ce papier les conséquences néfastes à courte et moyenne échéance qui peuvent résulter d'une interpolation brutale des sorties d'un modèle de circulation générale afin d'initialiser et de forcer un modèle côtier à haute résolution le long de ses conditions aux limites ouvertes. Nous détaillons alors les apports d'une méthode d'initialisation variationnelle tridimensionnelle. (C) 2001 Ifremer/CNRS/IRD/Éditions scientifiques et médicales Elsevier SAS

\section{Northern Current / Gulf of Lions / variational initialization / downscaling / continental shelf break}

Courant Nord / golfe du Lion / initialisation variationnelle / cascade d'échelles / talus continental

*Correspondence and reprints: fax: +33 561332790 .

E-mail address: aucf@aero.obs-mip.fr (F. Auclair). 


\section{INTRODUCTION}

In the geostrophic approximation, the large-scale currents are constrained to flow along the continental shelf breaks by their vorticity balance and have no impact on the circulation over the continental shelf itself. However, following wind bursts or various instabilities, such currents can penetrate over the shelf and their position and dynamics are responsible for a large part of the exchanges between the deep ocean and the coastal regions.

A consistent modelling of coastal shelf areas is thus intimately dependent on the correct understanding and on the accurate representation of the regional scale circulation. This is particularly true in the region of the western Mediterranean and in particular in the Gulf of Lions. A good knowledge of the main characteristics of the Northern Current (NC) and of its temporal evolution is indeed required to clearly understand the dynamics of the Gulf of Lions. A bad evaluation of the interactions of the current with the topography of the steep shelf break leads for instance to large errors in the position and the strength of the in-coming or out-going water masses on the continental shelf. However, an ocean general circulation model (OGCM) cannot deal properly with the numerous canyons of the shelf breaks due to its coarse resolution. The resulting water exchanges through the shelf break are thus rather homogeneous and their use as an openboundary forcing or as an initial field in a high resolution model of the shelf is inaccurate.

In this paper, we focus on the problem of downscaling the basin scale circulation given by an OGCM in order to initialize and force along its open boundaries a high resolution model of the continental shelf. We show the spurious consequences of a crude interpolation of the basin scale circulation and propose a downscaling technique based on a variational initialization technique. The eastern part of the Gulf of Lions is studied with a particular interest to the modelling of the interaction of the NC with the shelf of the Gulf of Lions in the region of Marseille.

Section 2 is a presentation of the hydrodynamical constraints in the region and of the resulting modelling set-up, a particular attention being brought to the specification of the general circulation. Sections 3 and 4 show a comparison of two experiments based on different methods to initialize and force the high resolution model along its open boundaries. The first one (named Experi- ment INT) uses 'crudely interpolated' fields as initialization and open boundary forcing while the second one (named Experiment ANA) is initialized and forced with an 'analysis' of these interpolated fields following the method proposed by Auclair et al. (2000a, 2000b). The comparisons are shown after respectively a few hours and a few days, i.e. during the adjustment period following the initialization and when the transients are eventually damped out. Section 5 shows the importance of a low horizontal diffusion coefficient.

\section{INITIALIZATION AND OPEN BOUNDARY FORCING}

\subsection{Hydrodynamics}

The NC constitutes a well identified component of the general circulation of the western Mediterranean basin from the Ligurian sea to the Provençal and Catalan coasts; it is thus often called the Liguro-ProvençoCatalan Current. Its structure has been found to evolve along this path in so far as it was shown to be composed of two climatological forcing (Béthoux et al. 1988). The coastal freshwater input in the Tyrrhenian sea leads to a density driven current maximum in early winter CAstraldi and Gasparini. 1992; Alberola et al. 1995 while a second component made of a rim current is geostrophotically forced by the deep water formation Crépon and Boukthir, 1987; Conan and Millot, 1995) and reaches a maximum in late winter. The $\mathrm{NC}$ is basically formed of Modified Atlantic Water (down to 300-400 m), a thin layer of Winter Intermediate Water, Ligurian Intermediate Water (down to 600-700 m) and eventually Western Mediterranean Deep Water (down to the bottom) CConan and Millot, 1995. Its total discharge varies from about $1.6 \mathrm{~Sv}$ in the middle of winter to about $1 \mathrm{~Sv}$ in summer (Alherola, et al, 1995).

Dynamically, the NC constitutes an interesting entity as it is baroclinically unstable in winter with a strong meandering activity over periods going from a few days to $20 \mathrm{~d}$ (Crépon et al. 1982). The resulting barotropic turbulence associated with eddy-like structures Carawx and Austin, 1984) and tongues (Millot, 1991) is thus believed to result from the interaction of its hydrological structure, the severe atmospheric forcing, the margin orientation and the canyon topography (Durrieu de 
Madron et al_.1990) In the region of Marseille, its core can be found either 35 or $20 \mathrm{~km}$ offshore over a period of a week.

This has important consequences in terms of observing and modelling strategies. Monthly or even semi-monthly observations are indeed undersampling its variability Conan and Millot 1995. Observations must be carried out on a daily to weekly basis and satellite altimetry and remote sensing thus appear to be essential tools. It also implies a modelling strategy including both climatological modelling of the Tyrrhenian and deep water formation forcing and small-scale and high frequency modelling of the interactions of the $\mathrm{NC}$ with the shelf break and the coastal areas.

\subsection{The biased specification of the regional scale circulation}

A correct modelling of the entrance of the NC over the shelf of the Gulf of Lions requires in particular an accurate representation of the various canyons which are spread along the shelf break. A grid scale of $1.5 \mathrm{~km}$ has thus been chosen to study the region of Marseille with the 3D primitive equation free-surface model Symphonie Estournel et al. 1997: Marsaleix et al. 1998). It is based on a mode splitting approach Blumberg and Mellor 1987). To provide a correct representation of the bottom current in steep topography areas, the 3D primitive equations are discretized on a staggered C-grid CArakawa and Lamb, 1977), with a two-fold sigma-coordinate. This high resolution small extent domain (Ggure 1 ) is centred on the very first canyon that the NC encountered when reaching the shelf break of the Gulf of Lions. The complete characteristics of the high resolution model implementation are given in table.

The western Mediterranean regional model OPA (Ocean PArallel model, Herbaud, 1994; Herbaud et al. 1996) provides the initial field and the open boundary conditions for the year 1992. The NC (figure 2) can be recognized along the northern coast together with the cyclonic winter gyre that participates in the preconditioning of the deep convection process. OPA is a 3D primitive equation model implemented on a staggered $\mathrm{C}$-grid with a resolution of $1 / 8$ th of a degree in longitude and 1/10th of a degree in latitude.

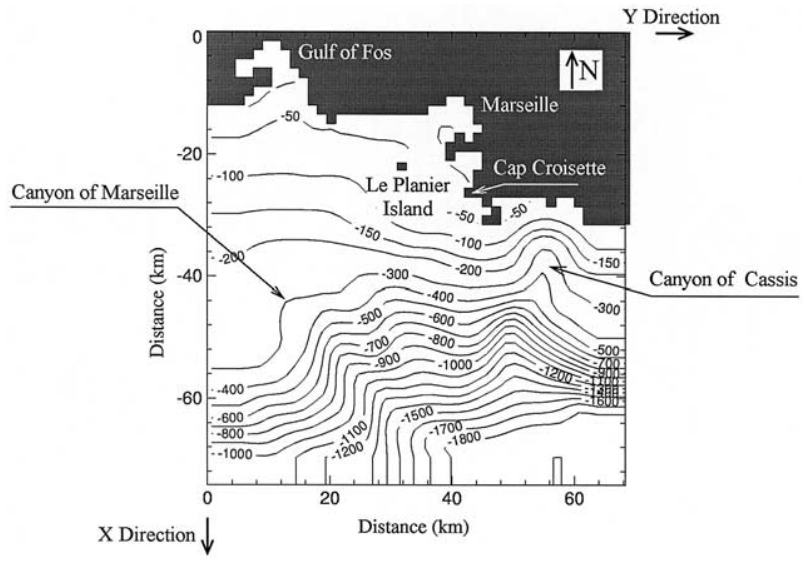

Figure 1. Bottom topography (given in meters) of the high resolution small extent domain in the region of Marseille.

It has two main particularities with respect to the high resolution model. First of all, it uses the rigid lid approximation, which means that the surface elevation anomaly is a diagnostic variable and the resulting transport has a vanishing divergence. As a consequence, the physics of the models are different not only due to the difference in grid scale - the regional scale model cannot represent the 7 to $11 \mathrm{~km}$ first Rossby radius (Grilliand Pinardi, 1998 - but also due to the basic assumptions used to deal with the external mode.

A second particularity is its z-coordinate (31 levels) which leads in particular to a different representation of the bottom topography from the high resolution model. Horizontally, about six grid points of the high resolution model can be found for one point of the regional scale model (figure 3a). However, the major problem is related

Table I. Main characteristics of Experiments INT and ANA.

\begin{tabular}{cc}
\hline Horizontal grid scale & $1.5 \mathrm{~km} \times 1.5 \mathrm{~km}$ \\
Number of layers & 16 \\
Sigma layers & $\begin{array}{c}\text { Two-fold Sigma layers (Auclair } \\
\text { et al., 2000b) with a 200-m } \\
\text { threshold }\end{array}$ \\
External mode time step & $3 \mathrm{~s}$ \\
Internal mode time step & $90 \mathrm{~s}$ \\
Advective scheme & Upstream \\
Horizontal diffusion & $30 \mathrm{~m}^{2} \cdot \mathrm{s}^{-1}$ \\
in momentum equation & Gaspar et al. (1990) \\
Turbulent scheme & Orlanski (1976) and relaxation \\
Open-boundary conditions & f-plan, $\mathrm{f}=9.92015$ \\
Coriolis parameter &
\end{tabular}




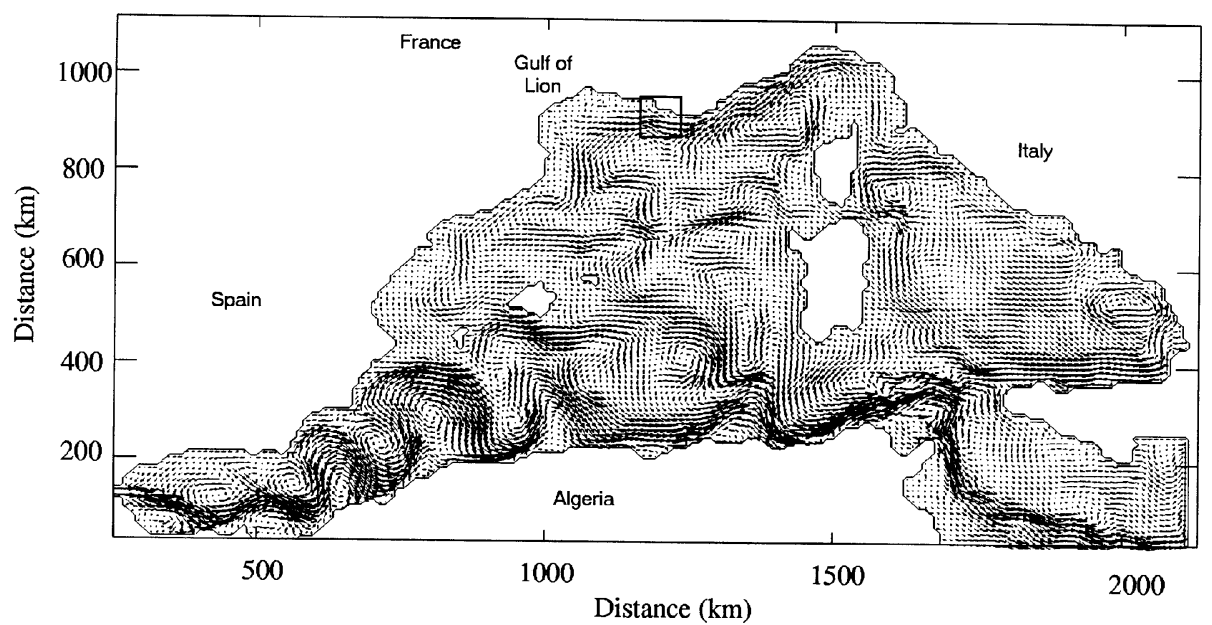

Figure 2. Surface circulation at 5-m deep for 25 November 1992 $V_{\max }=82.44 \mathrm{~cm} \cdot \mathrm{s}^{-1}$. Black rectangle: location of the high resolution grid. to the different representation of the coastline. The high resolution fields in the region of Fos and Cap Croisette (south of Marseille) must indeed be extrapolated and a crude extrapolation of the velocity field in such regions leads to the appearance of non-vanishing transports. If such transports are used to initialize the high resolution model, they generate large amplitude gravity waves during the very first hours of simulation (Amclair et al 2000a. The high resolution representation of this cap stands across the regional scale incoming branch of the $\mathrm{NC}$, creating a region of convergence of this current upstream of the cap and a region of divergence downstream. Vertically, figure 3b shows that small-scale bottom topography accidents such as the canyon of Marseille (between $43^{\circ}$ and $43.3^{\circ} \mathrm{N}$ ) can obviously not be correctly modelled using the regional scale grid. Inside some narrow canyons, the difference in depth between the two grids can reach $100 \mathrm{~m}$. Consequently, the extrapolation of the regional scale fields on the high resolution grid is rather arbitrary. In regions with steep topography gradients, both models show important shortcomings. Sigmacoordinate models are well known to suffer from the difficulty of representing the horizontal pressure gradient over regions with steep topography gradients Haney 1991. On the other hand, z-coordinates lead to a step-like bottom topography and are therefore not well-adapted to an accurate representation of bottom current and advective processes along the shelf break Beckmann, 1998). A good modelling of the bottom dynamics is thus difficult and depends mainly on how well the bias of both models are taken into account.
As a consequence, the initialization and the forcing of the high resolution model along its open boundaries using this regional scale circulation raise numerous problems such as:

- the different physics of the models;

- the likely destruction of the fundamental balance of the field when interpolated on the high resolution bottom topography CAuclair et al. 2000a);

- the difference of nature of the truncation errors in steep bottom topography areas in $\mathrm{z}^{-}$and sigmacoordinates (Amclair et al, 2000h).

\subsection{A 3D variational initialization technique to analyse the regional scale circulation}

A 3D variational initialization technique (Auclair et al. 2000a has been implemented to analyse both the initial field and the open boundary forcing. It was shown that such a method reduces drastically the amplitude of the numerical transient processes following the initialization by reducing the misfit of the initial field. As importantly, the adjustment of the initial geostrophic component of the current reduces the amplitude of the horizontal pressure gradient truncation errors due to the use of Sigma-coordinate in steep topography gradient areas CAuclair et al.2000b. A short description of the method is now given. 

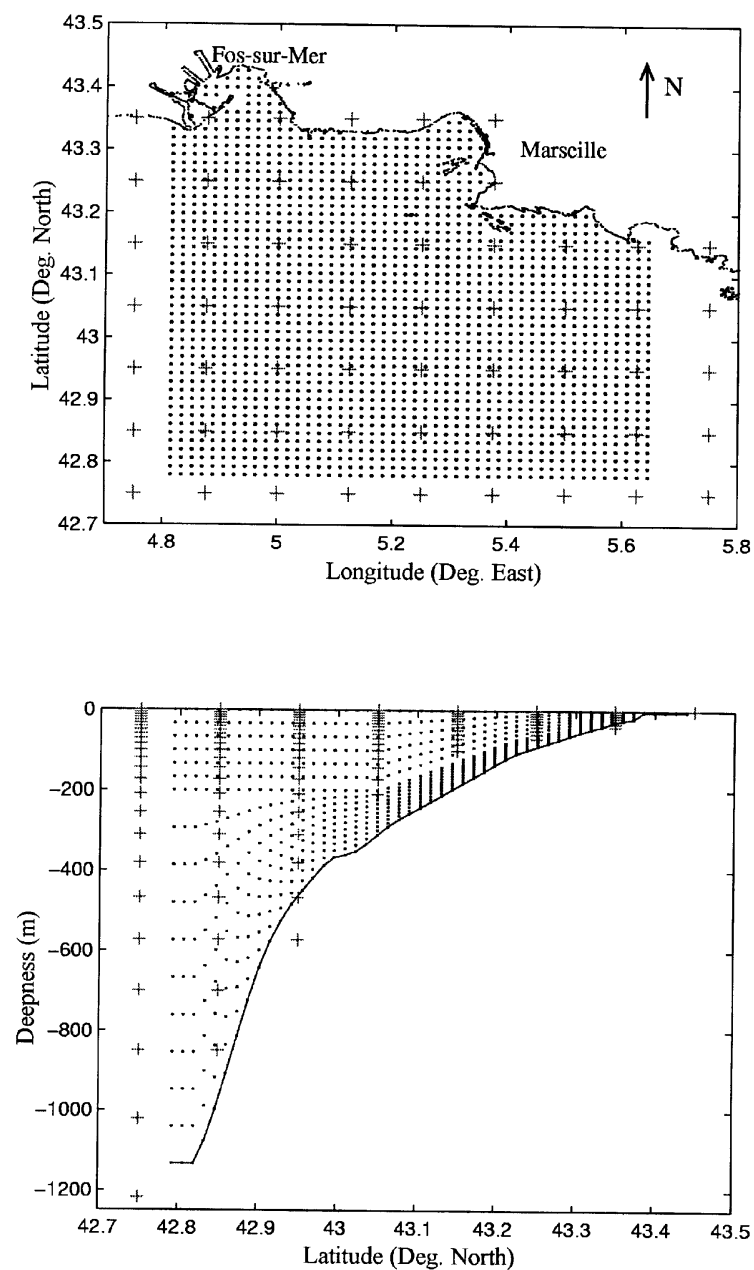

Figure 3. Comparison of the OPA (+) and Symphonie (dots) grids. (a) Horizontal grid, coastline from the US Defense Mapping Agency's world Vector Shoreline. (b) Vertical grid at $5^{\circ} \mathrm{E}$; solid line: high resolution model bathymetry.

The coastal high resolution model is written in a compact form:

$$
x^{f}\left(t_{i+1}\right)=M_{i}\left[x^{f}\left(t_{i}\right)\right]
$$

where $x$ is the model state vector, $M$ the dynamics operator and $t$ is time. The notations are the classic notations given in Ide et al. (1997), in which the superscripts $f, a$ and $o$ stand respectively for forecast, analysis and observation. A first 'crude' interpolated 'background or first guess state vector' $x^{b}\left(t_{0}\right)$ is obtained using a smooth Gaussian interpolation on the high resolution grid (see appendix). Among the advantages of such a filter are its simplicity, its easy and well-understood tuning (Bretherton et al., 1976). However, it must be carefully tuned in so far as it can over-smooth the regional scale fields.

In the next step, an optimal perturbation of this first guess is computed by minimizing the cost function:

$$
\begin{aligned}
& J=\left(x_{0}^{a}-x_{0}^{b}\right)^{T} B_{0}^{-1}\left(x_{0}^{a}-x_{0}^{b}\right)+ \\
& \quad\left[y^{0}-\left(H_{0} x^{a}\left(t_{0}\right)-F_{0}\right)\right]^{T} R_{0}^{-1}\left[y^{0}-\left(H_{0} x^{a}\left(t_{0}\right)-F_{0}\right)\right]
\end{aligned}
$$

$R_{0}$ is the model error covariance matrix, $B_{0}$ is the approximate error covariance matrix for the interpolated field $x^{b}\left(t_{0}\right)$, and $H_{0}$ is the observation operator based in particular on the tangent high resolution coastal model $M_{(1)}$ in the vicinity of $x^{b}$ and $F_{0}$ is the forcing vector in (1). $y^{0}$ is the 'observation' vector: it indicates the true values of the constrains like the tendencies of the tangent linear equations, or some particular local or global observations. These tendencies can be specified from the regional scale models or from observations. In such a case, the analysis field is forced to have first order dynamics in agreement with these output data or observations. In the present study and as a preliminary step, the initial tendencies have been forced to vanish $\left(y^{0}=0\right)$. The analysis field is thus made close to an equilibrium field by filtering out initial high frequency processes.

The analysis field is eventually obtained by solving the linear system given by:

$$
x^{a}\left(t_{0}\right)=x^{b}\left(t_{0}\right)+K_{0}\left[y^{0}-\left(H_{0} x^{b}\left(t_{0}\right)-F_{0}\right)\right]
$$

where the gain $K_{0}$ is provided by:

$$
K_{0}=B_{0} H_{0}^{T}\left(H_{0} B_{0} H_{0}^{T}+R_{0}\right)^{-1}
$$

The complete algorithm is described in Auclair et al 2000a), and the details of the implementation used for the present study are given in tables In and III Table II shows in particular a complete description of the error covariance matrices $B_{0}$ and $R_{0}$. $B_{0}$ is decomposed in two parts: one computed with homogeneity assumptions, the second being a parameterization of non-homogeneous and non-isotropic error structures due to the bathymetric constraints. This latest parameterization is composed of a component based on the difference of bathymetry between the regional and coastal models and an extradiagonal component standing for the stronger correlation of the geostrophic current along the bathymetry. This non-homogeneous and non-isotropic error covariance 
Table II. Main parameters of the inverse method.

Interpolation: filtering $R_{L}$

Control variables

Cost function and observation operator

Error covariance matrix $B_{0}$

Error covariance matrix $R_{0}$

Algorithm used (4-step scheme)
Gaussian filter (Appendix A)

$R_{L}=5 \mathrm{~km}$

Truncation error optimization: density $(\rho)$ and surface elevation $(\eta)$

External mode: transport $(\bar{U}, \bar{V})$,depth-mean density $(\bar{\rho})$ and surface elevation $(\eta)$

Internal mode: velocity $(u, v)$ and density $(\rho)$

$J=\left(x_{0}^{a}-x_{0}^{b}\right)^{T} B_{0}^{-1}\left(x_{0}^{a}-x_{0}^{b}\right)+\left(y_{0}-H_{0} x_{0}^{a}+F_{0}\right)^{T} R_{0}^{-1}\left(y_{0}-H_{0} x_{0}^{a}+F_{0}\right)$

Numerically: $J=J_{\text {geo }}+J_{\text {ext }}+J_{i n t}+J_{\text {TS }}$ (see the algorithm bellow)

$H_{0}$ is obtained from the six equations of the linear tangent model and from the C-grid pressure gradient and Brunt-Väisälä frequency discretization, and $F_{0}$ contains the various surface fluxes

$y_{0}=\left(\begin{array}{c}0 \\ y_{0}^{2}\end{array}\right)$ where $y_{0}^{2}$ contains the geostrophic current from the regional scale model, and the first guess Brunt-Väisälä frequency.

Truncation error optimization: $B_{0}$ is obtained from the slope parameter

External and internal mode analysis: Homogeneous spectrum; anisotropic covariance (Auclair et al., 2000a)

Pressure gradient truncation error analysis: $R_{0}$ is chosen so that $\delta \rho_{\mathrm{MAX}}<0.13 \mathrm{~kg} \cdot \mathrm{m}^{3}$ and $\delta \eta_{\mathrm{MAX}}<1 \mathrm{~mm}$ External and internal mode analysis: $R_{0}$ is computed from a $10-\mathrm{d}$ run and filtered horizontally at $10 \mathrm{~km}$, vanishing tendency errors.

Optimization of the pressure field to reduce the amplitude of the horizontal pressure gradient truncation errors $\left(J_{\text {geo }}\right)$,

Followed by an optimization of the external mode control variables $\left(J_{\text {ext }}\right)$

Optimization of the internal mode control variables (sixteen independent layers) $\left(J_{\text {int }}\right)$

Second optimization of the external mode control variables $\left(J_{\text {ext }}\right)$

Temperature and salinity optimization to obtain the analysis density field $\left(J_{\mathrm{TS}}\right)$. matrix $B_{0}$ leads to an analysis field that is very similar to the background interpolated solution $x_{b}$ far from the shelf break and the regions with large bathymetry gradients while larger adjustments are computed anywhere else. A complete description of the error covariance matrices in a well-documented case is given in Auclair et_al_(2000a)
The initial field is successively optimized based on geostrophic constraints and then constraints related to the external and internal modes (4-step scheme described in table $(1)$. In table $\mathrm{Il}$, the conservation of mass is given as a strong constraint in a 'Sasaki' sense (Sasaki.1960). i.e. the local tendency of the mass balance is forced to be

Table III. Computational characteristics of the analysis.

\begin{tabular}{|c|c|c|c|c|c|}
\hline & Characteristics & $\begin{array}{l}\text { No. of } \\
\text { inversions }\end{array}$ & $\begin{array}{c}\text { No. of } \\
\text { variables }\end{array}$ & $\begin{array}{l}\text { No. of } \\
\text { constraints }\end{array}$ & $\begin{array}{l}\text { Total } \\
\text { No. of non- } \\
\text { zero elements }\end{array}$ \\
\hline Truncation errors & $\begin{array}{l}\text { Geostrophy } \\
\text { Brunt-Väisälä frequency }\end{array}$ & 1 & 29937 & 80895 & 1087850 \\
\hline External mode 1 st iteration & $\begin{array}{l}\text { Momentum equations } \\
\text { Conservation of mass } \\
\text { (strong constraint) } \\
\text { Incoming transport of the } \mathrm{NC}\end{array}$ & 1 & 5286 & $\begin{array}{c}5286 \\
\text { (1 } 761 \text { strong constraints) }\end{array}$ & 95322 \\
\hline Internal mode & $\begin{array}{l}\text { Momentum equations } \\
\text { Incoming transport of the } \mathrm{NC}\end{array}$ & 16 & 5283 & 3523 & 65403 \\
\hline External mode 2nd iteration & idem 'External mode 1' & 1 & 5286 & $\begin{array}{c}5286 \\
\text { (1 } 761 \text { strong constraints) }\end{array}$ & 95322 \\
\hline
\end{tabular}


exactly zero. The complete computation of the analysis field requires approximately the equivalent of 3 to $5 \mathrm{~d}$ computation with the high resolution model over the domain. The most important part of the computation is dedicated to the inversion of the optimal systems.

The analysis field $x^{a}\left(t_{0}\right)$ can then be used to initialize the high resolution model. Various analysis of the regional scale model output are also carried out at different times during the period (after 6 and $16 \mathrm{~d}$ ) and are linearly interpolated in time to provide the open boundary conditions. As a consequence this simple open boundary, conditions are not optimal in so far as no time-dependent criterion is used to compute some optimal external fields toward which the high resolution fields could be relaxed. However, the basin scale circulation that is specified along the open boundaries is optimally adjusted to the high resolution model constraints, in the same way the initial field is.

To study the problems related to the specification of the regional scale circulation into a high resolution model, two twin experiments have been carried out. One is initialized and forced along its open boundaries using a crude interpolation of the dynamics of the regional scale model (Experiment INT), the other is initialized and forced using an analysis of these crudely interpolated fields (Experiment ANA). The differences between these twin experiments are then compared at two different scales. First, the transient processes following the initialization are studied (after only a few hours), then on a longer scale (after a few days) the consequences of these processes are studied together with the consequences of the use of different regional scale circulations along the boundaries.

\subsection{Atmospheric forcing}

A period of 2 weeks has been chosen from 25 November 1992 to 11 December 1992. The atmospheric forcing (wind and heat fluxes) are the same as the one used for the regional scale model and are interpolated on the high resolution grid. The average of the main atmospheric parameters over the domain is shown in figure 4 . The freshwater input due to the precipitation and to the Rhone river output has been neglected over the period. The precipitations were indeed rather low and the Rhone river mouth is at the edge of the domain. Its dynamics has previously been studied with the same coastal model (a)

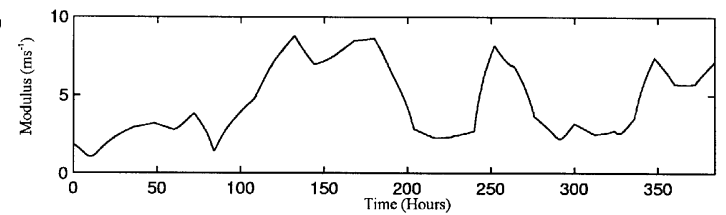

(b)

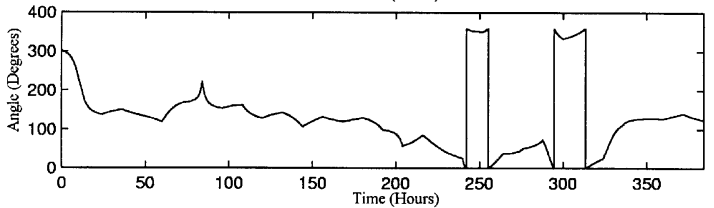

(c)
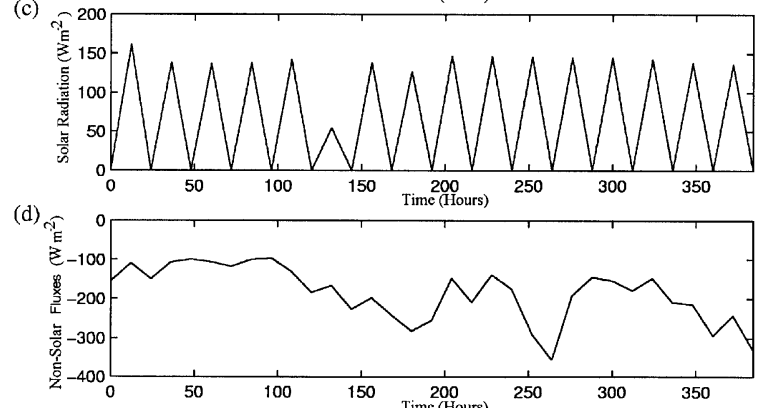

(e)

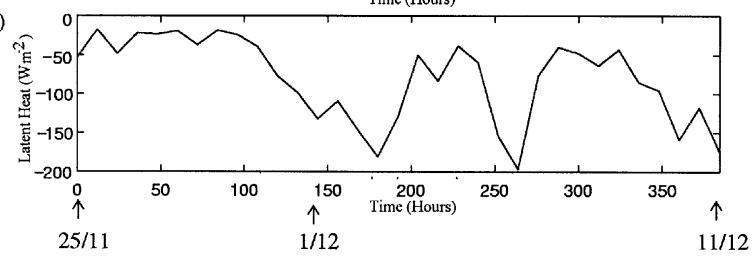

Figure 4. Atmospheric forcing averaged over the domain from 25 November to 11 December. (a) Wind modulus $\left(\mathrm{m} \cdot \mathrm{s}^{-1}\right)$, (b) wind direction (degree), (c) solar radiation $\left(\mathrm{W} \cdot \mathrm{m}^{-2}\right),($ d) long wave, sensible heat and latent heat surface fluxes $\left(\mathrm{W} \cdot \mathrm{m}^{-2}\right)$, (e) latent heat flux $\left(\mathrm{W} \cdot \mathrm{m}^{-2}\right.$ ).

Estournel et al. 1997; Marsaleix et al. 1998: Estournel etal, 2001) and is not relevant to the study of the impact of the regional scale circulation. However, some results on its interactions with the regional scale circulations can be found in Auclair (1999 Appendix D).

The first $5 \mathrm{~d}$ of the period show small south-south-east wind forcing (lower than $3 \mathrm{~m} \cdot \mathrm{s}^{-1}$ ) and low heat fluxes (figure 4). An increase of the south-east wind forcing and a cooling of the atmosphere during 4 to $5 \mathrm{~d}$ follow this period of relative calm. Then, we can notice two wind bursts in the second half of the period. The first one corresponding to a Mistral event has important consequences on the entrance of the $\mathrm{NC}$ over the shelf.

The initial period of calm provides a clear separation of the processes due the atmospheric forcing and those due 
(a)

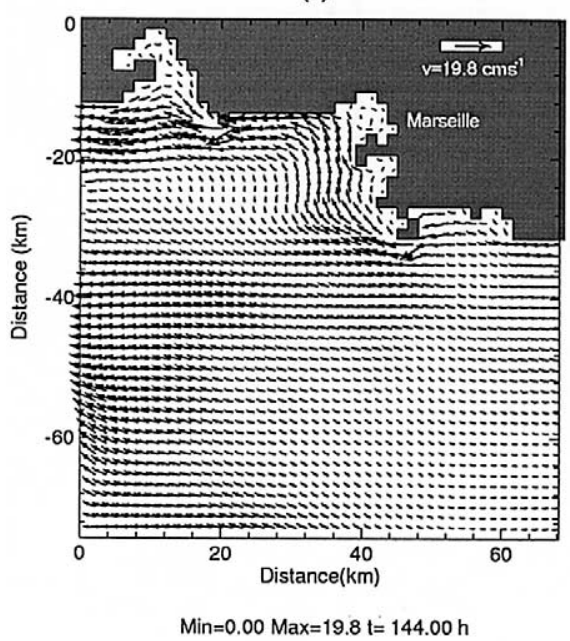

(b)

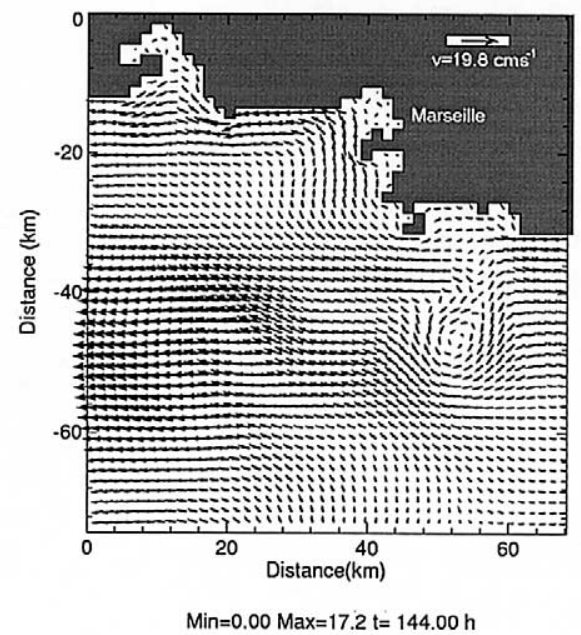

Figure 5. Depth averaged velocity on 25 November (initial field). (a) Regional scale model output on the high resolution grid using a Gaussian interpolation, (b) analysis of field (a) with the inverse method. to the numerical adjustment of the model that follows its initialization.

\section{TRANSIENT PROCESSES}

\subsection{Initial depth averaged velocity}

The depth averaged velocity for both initial fields is given in figure 5a and $b$, showing the same 'regional' scale circulation. In particular, the NC penetrates over the shelf offshore through the canyon of Marseille and along the coast in the region of Cap Croisette. However, two main differences can be noticed. The first one concerns the areas of strong convergence or divergence of the crudely interpolated field in the region of Cap Croisette (see comments in foure 3 ), and in the gulfs of Marseille and Fos. The crudely interpolated circulation penetrates the continental shelf orthogonaly to the bottom topography, in particular around the location of the island of Le Planier (not represented on the model grid).

The main improvements due to the analysis of this field $($ fgure $5 b$ ) are the appearance of a coastal jet of about $10-\mathrm{km}$ width and the reduction of the areas of strong divergence and convergence. It can be shown that the analysis of the crudely interpolated circulation reduces drastically the Jebar terms (Auclair et al. 2000a), indicating a better adjustment of the pressure gradients to the bottom topography forcing.

\subsection{Potential horizontal pressure gradient truncation errors}

Eigure 6 is a meridian section of the 'potential' horizontal pressure gradient truncation error due to the use of Sigma-coordinates. Based on the results obtained in Auclair et al. (2000b, these potential errors are the differences between the geostrophic current computed on the high resolution Sigma-grid and the geostrophic current computed on the corresponding 1-m vertical resolution $\mathrm{Z}$-grid over the same domain. In the first case, the density is interpolated on the Sigma-grid before the computation of the horizontal pressure gradient whereas in the second, the geostrophic current is computed first on a horizontal grid before being interpolated on the Sigma-grid and has no 'Sigma-horizontal pressure gradient truncation errors'. The maximum of the potential truncation error is of $3 \mathrm{~cm} \cdot \mathrm{s}^{-1}$ in this section and can reach $6 \mathrm{~cm} \cdot \mathrm{s}^{-1}$ in small extent areas along the canyon of Cassis. As indicated in table the adjustment of the geostrophic component of the analysis field with a maximum modification of the pressure field of $0.13 \mathrm{~kg} \cdot \mathrm{m}^{-3}$ for the density and $1 \mathrm{~mm}$ for the surface elevation anomaly, reduces these potential truncation errors to less than $1.5 \mathrm{~cm} \cdot \mathrm{s}^{-1}$. More importantly, the well structured currents which can be observed along the shelf break in figure disappear and are replaced by sparse errors that rapidly disappear during the first hours of run. It is eventually worthy to note that the use of a two-fold Sigma-coordinate instead of a simple one-fold 


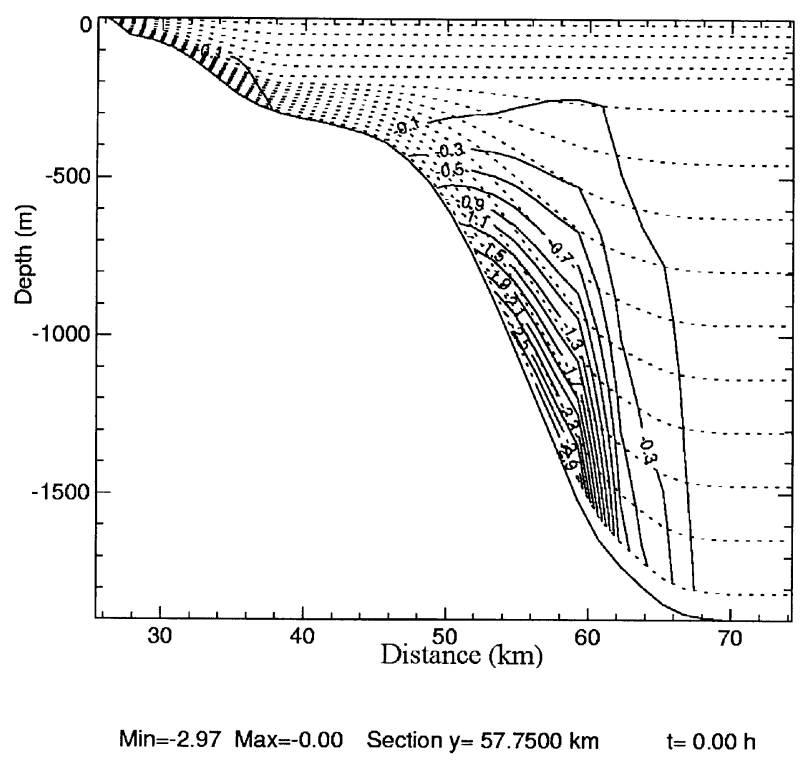

Figure 6. Meridian section through the canyon of Cassis of the difference between the geostrophic component of the current computed on a Z-grid and the same component computed on the model Sigma-grid using the initial pressure field of Experiment INT (in $\mathrm{cm} \cdot \mathrm{s}^{-1}$ ). The dashed lines give the location of the Sigma levels.

Sigma-coordinate already reduced the amplitude of the mean potential truncation errors by a factor of five (Auclair et al, 2000b)

\subsection{External gravity waves and transients}

A comparison of foure $7 d$ and $\mathrm{B}$ shows that the time variations of the surface elevation anomaly during the first $2 \mathrm{~d}$ simulation have been decreased by at least two orders of magnitude due to the analysis of the pressure field. This can be explained by the drastic reduction of the amplitude of the external gravity waves due to the adjustment of the initial field to the high resolution bottom topography and to the physics of the high resolution model. The largest amplitudes of the surface elevation anomaly can be found in the shallow regions and last for about $2 \mathrm{~d}$ until the circulation adjusts to the high resolution bottom topography constraints. In Experiment ANA, the circulation does not show any deformations because the initial circulation already satisfies these constraints.

Still in Experiment ANA (figure 8d and C), the current does not vary significantly during the very first hours (a)

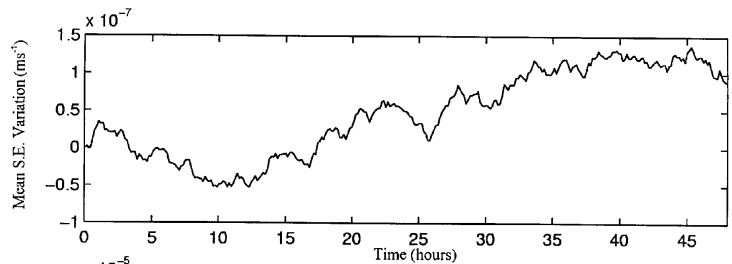

(b)

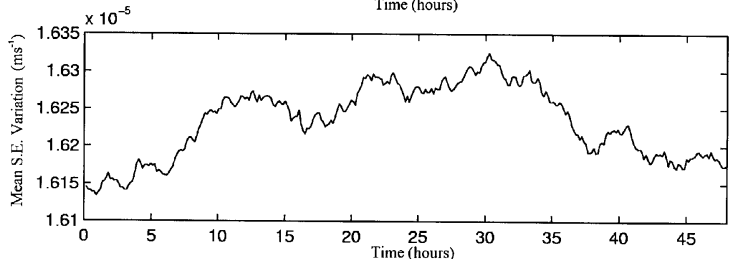

Figure 7. Adjustment of the high resolution model during the first $2 \mathrm{~d}$ simulation (averages over the domain). (a) Time variation of the mean surface elevation anomaly in Experiment $A N A\left(\mathrm{~m} \cdot \mathrm{s}^{-1}\right)$, (b) time variation of the mean surface elevation anomaly in Experiment $I N T$ $\left(\mathrm{m} \cdot \mathrm{s}^{-1}\right)$.

whereas in Experiment INT (figure 8b and b) the current varies sharply during the first day following the initialization. During this spin-up period, the high resolution dynamics obtained in Experiment INT must therefore be considered with a lot of care: the external mode solution in particular is dubious.

\subsection{Differences after $1 \mathrm{~h}$ simulation}

Figure 9 shows the differences between Experiments INT and $A N A$ after only $1 \mathrm{~h}$. As a consequence of this drastic reduction of the amplitude of the perturbation of the external mode in Experiment ANA with respect to Experiment INT, the maps of the differences between Experiments INT and ANA (Ggure 9) give a very good estimate of the amplitude of the transients in Experiment INT.

The consequences of the oscillations of the surface elevation in Experiment INT (Goure 9d) and of the resulting gravity waves that are propagating in this simulation (figure $9 b$ ) can easily be noticed. These strong oscillations of the surface elevation anomaly (fgure 9d) appear indeed during the very first hours of simulation in Experiment INT in areas where the initial transport is strongly convergent or divergent (figure $5 d$ ).

A vertical section of the north/south current (figure 9d) shows large differences in the way the NC enters over the shelf of the Gulf of Lions. Following the interpolated 
(a)

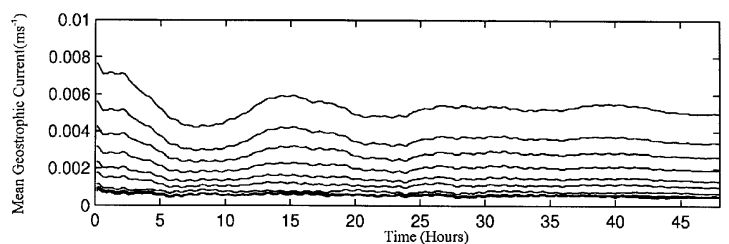

(b)

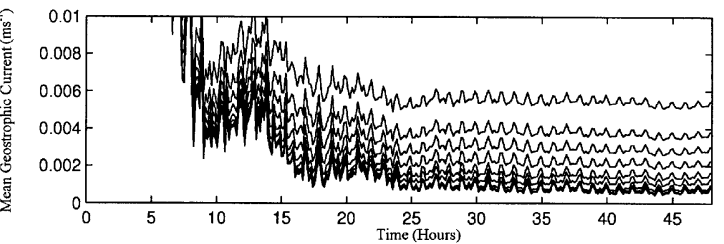

(c)

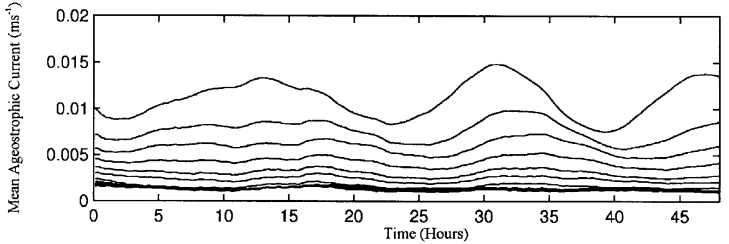

(d)

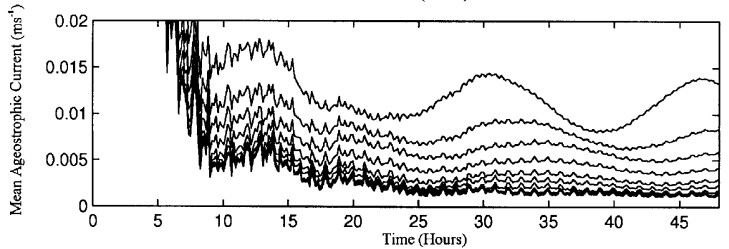

Figure 8. Adjustment of the high resolution model during the first $2 \mathrm{~d}$ simulation (averages over the domain, one curve per Sigma level). (a) Geostrophic current in Experiment $A N A\left(\mathrm{~m} \cdot \mathrm{s}^{-1}\right)$, (b) geostrophic current in Experiment INT $\left(\mathrm{m} \cdot \mathrm{s}^{-1}\right)$, (c) ageostrophic current in Experiment $A N A\left(\mathrm{~m} \cdot \mathrm{s}^{-1}\right)$, (d) ageostrophic current in Experiment $I N T\left(\mathrm{~m} \cdot \mathrm{s}^{-1}\right)$.

regional scale circulation, the current in Experiment INT still has a strong ageostrophic component toward the north-west, which is crossing the isobaths offshore Cap Croisette (figure 9d). In contrast, in Experiment ANA, the current spreads inside the canyon and shows a strong component at the bottom of the canyon (foure 9d). In Experiment $I N T$, the adjustment of the incoming branch of the $\mathrm{NC}$ on the shelf indeed needs 1 to $2 \mathrm{~d}$ to adjust to the high resolution bottom topography forcing.

The same observations can be made concerning the bottom current inside the canyon of Marseille (figure 9d). The bottom current difference shows that the regions of small-scale topography accidents (canyon of Cassis Goure 9d; Gulf of Marseille - figure 9d; ...) are spread with strong currents with large amplitude variations in Experiment $I N T$.

The strong ageostrophic currents found in Experiment INT have never been observed in the region of Marseille
Conan and Millot_1995) and cannot be explained by atmospheric forcing which are particularly weak during the period. They disappear after the adjustment period (of the order of the inertial period) leading to the conclusion that spurious structures are introduced by the crude initialization and can be drastically reduced by the variational initialization technique.

\section{LONG-TERM CONSEQUENCES OF THE INITIAL ADJUSTMENT}

\subsection{Analysis of the differences between experiments $I N T$ and $A N A$}

Experiments INT and ANA are now compared on a longer time scale in order to show that the transient processes have important consequences on the long-term model trajectory.

Figure $1 d$ shows a comparison of the depth averaged velocity in both experiments after $6 \mathrm{~d}$, i.e. at the end of the calm atmospheric forcing period. The depth averaged velocity obtained by interpolating the regional scale model output on the high resolution grid for 1 December (not shown) is very similar to the one observed $6 \mathrm{~d}$ before (fgure 5d) as a consequence of the weak atmospheric forcing. The coastal jet is mostly alimented on the shelf through the canyon of Cassis. The differences between Experiments INT and ANA are given in figure 10 after $6 \mathrm{~d}$. They reach $1.2 \mathrm{~cm} \cdot \mathrm{s}^{-1}$ along the shelf break (figure 10), and more than $2.5 \mathrm{~cm} \cdot \mathrm{s}^{-1}$ after $16 \mathrm{~d}$. Important differences can also be found along the southern open boundary (figure 10), mostly due to the difference between the regional scale forcing along this boundary. Indeed Experiment $I N T$ is forced by crudely interpolated fields whereas Experiment $A N A$ is forced by analysed fields. The underestimation of the coastal jet in Experiment INT in particular offshore the Gulf of Fos (1 to $2 \mathrm{~cm} \cdot \mathrm{s}^{-1}$ ) can also be seen. As time goes on, the amplitude of the coastal jet vanishes in Experiment INT whereas the incoming branch of the $\mathrm{NC}$ around Cap Croisette is still present and still rather strong in the regional scale circulation (not shown).

To understand the undergoing processes, the differences between Experiments INT and ANA are also analysed in Ggure 1$]$ for the surface elevation anomaly, the density, and the surface and bottom current after $6 \mathrm{~d}$. Three 


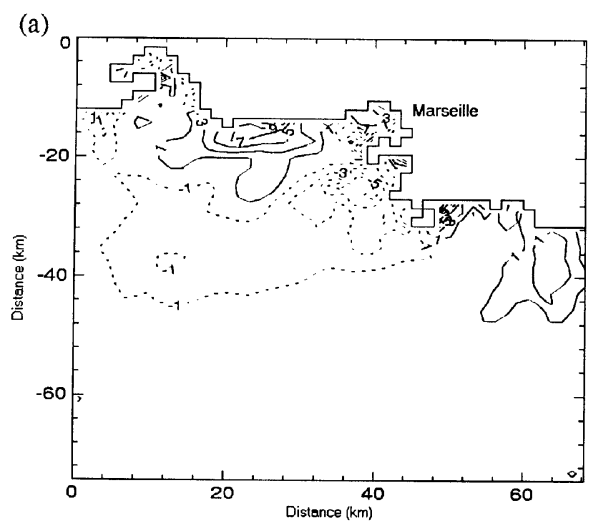

$\operatorname{Min}=-9.52 \operatorname{Max}=15.73 \mathrm{t}=1.00 \mathrm{~h}$

(c)

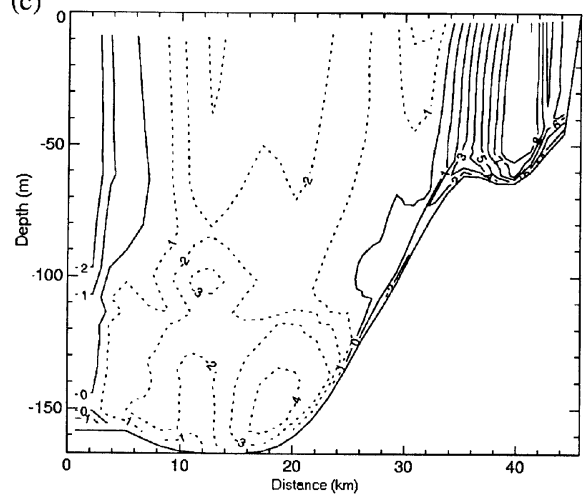

Min $=-4.35$ Max $=10.01$ Section $x=30.7500 \mathrm{~km}(l=21) t=1.00 \mathrm{~h}$

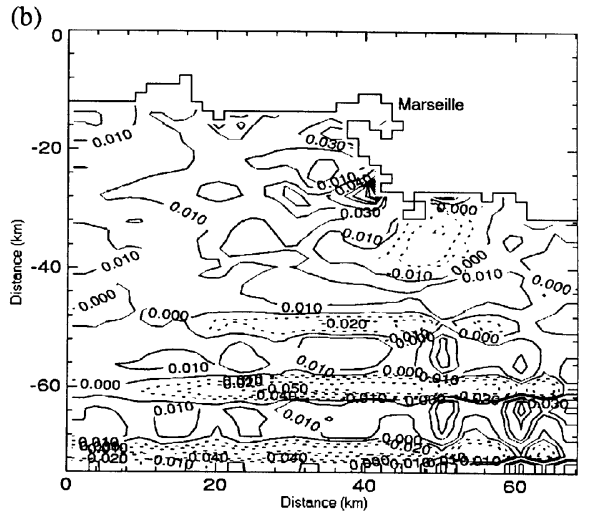

Min $=-0.06 \operatorname{Max}=0.15 \mathrm{z}=20 \mathrm{~m} \mathrm{t}=1.00 \mathrm{~h}$

(d)

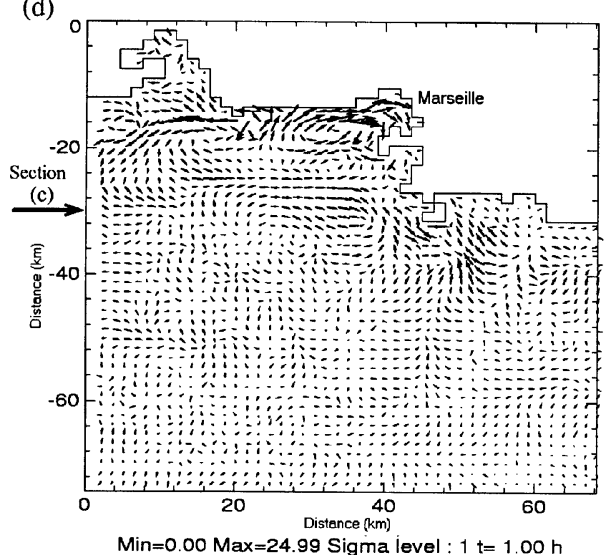

Figure 9. Differences between Experiments INT and ANA after 1 h. (a) Surface elevation anomaly $(\mathrm{cm}),(\mathbf{b})$ horizontal section of density at $20-\mathrm{m}$ deep $\left(\mathrm{kg} \cdot \mathrm{m}^{-3}\right),(\mathbf{c})$ zonal section of the current at shelf break $\left(\mathrm{cm} \cdot \mathrm{s}^{-1}\right)$, positive velocities are toward the south, (d) bottom current $\left(\mathrm{cm} \cdot \mathrm{s}^{-1}\right)$, lower Sigma layer. reasons can explain the differences: the reduction of the truncation errors, the reduction of the amplitude of the transient processes in Experiment ANA with respect to Experiment $I N T$, and eventually the analysis of the open boundary forcing fields in Experiment ANA.

Figure $11 d$ shows a large amplitude current following the shelf break which has the characteristics of a horizontal pressure gradient truncation error current. Its amplitude can reach $5 \mathrm{~cm} \cdot \mathrm{s}^{-1}$ along the shelf break. To clearly identify the nature of this current, a second analysis of the initial field has been carried out considering only the constraints related to the geostrophic current (not shown). This latest experiment is very close to Experiment INT except along the shelf break where the along shelf current disappears which clearly indicates that in Experiment INT this current is due to the horizontal pressure gradient truncation errors in the regions of steepest topography

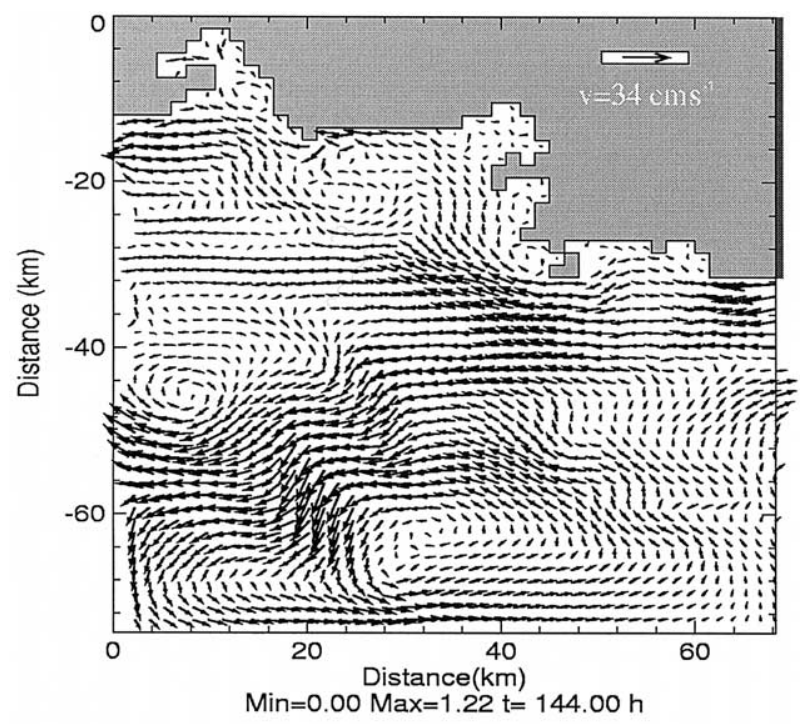

Figure 10. Depth averaged velocity after $6 \mathrm{~d}$ (1 December): differences between forecasts in Experiments INT and ANA. 


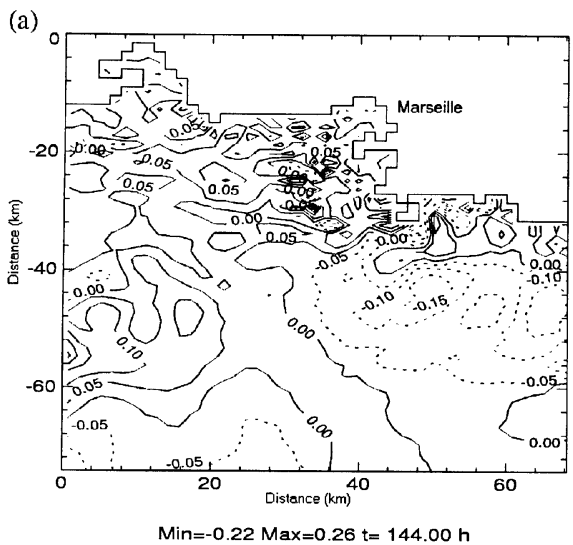

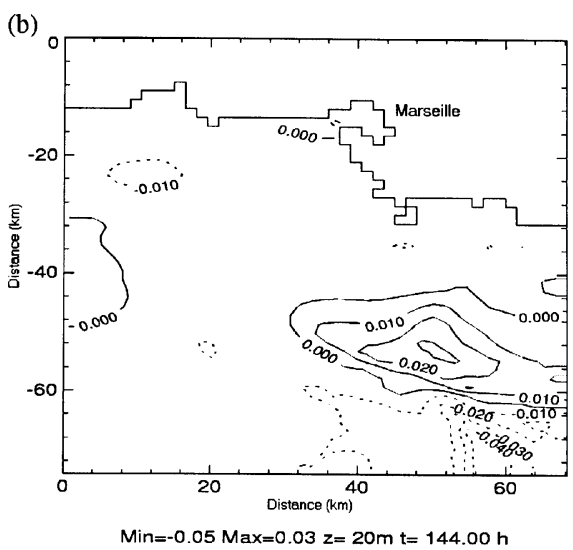

Min $=-0.05 \operatorname{Max}=0.03 \quad z=20 m \mathrm{t}=144.00 \mathrm{~h}$

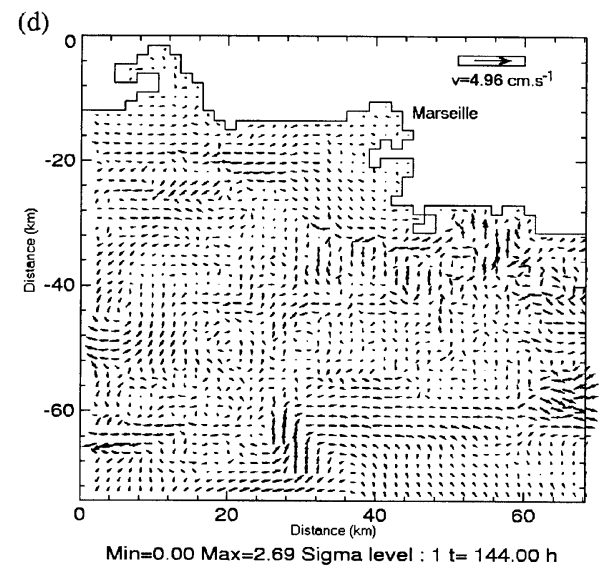

Figure 11. Differences between Experiments INT and ANA after 6 d. (a) Surface elevation anomaly (cm), (b) horizontal section of density at $20-\mathrm{m}$ deep $\left(\mathrm{kg} \cdot \mathrm{m}^{-3}\right),(\mathbf{c})$ surface current $\left(\mathrm{cm} \cdot \mathrm{s}^{-1}\right)$, upper Sigma layer, (d) bottom current $\left(\mathrm{cm} \cdot \mathrm{s}^{-1}\right)$, lower Sigma layer. gradients. Such truncation error currents decrease very slowly with time (Mellor et al. 1994). They are mostly located in the bottom layer (two-fold sigma-coordinates are being used) along the shelf break, i.e. where the bottom topography gradients are steep and the vertical density gradients are large.

The transient processes following the initialization are also responsible for the large differences on the pressure field between Experiments INT and ANA in particular in the gulfs of Fos and Marseille (Ggure $1 \mathrm{~b}$ ). Over the shelf of the Gulf of Lions, the pressure field in Experiment INT has been modified during the adjustment period. The modifications are advected by the current and thus concern an area whose extent increases downstream with time. Large differences could for instance be observed between Experiments INT and ANA in the surface elevation anomaly and density fields in the gulfs of Marseille and Fos after only a few hours of simulation. After a few days, these differences extend to the shelf, implying large differences in current and lead to different responses to atmospheric forcing. The resulting underestimate of the coastal jet, already observed after a few hours, becomes really unphysical with time though the regional scale circulation still shows a strong incoming branch of the $\mathrm{NC}$, at least as strong as it was on 25 November.

A third possibility can explain the differences between Experiments INT and ANA. Indeed the differences in the open boundary forcing can be felt far inside the domain. These differences are in particular large in the southern part of the domain where the $\mathrm{NC}$ has large amplitude (figure $11 \mathrm{~d}$ ). After $6 \mathrm{~d}$, the amplitude of such differences is less than $4 \mathrm{~cm} \cdot \mathrm{s}^{-1}$ close to the surface but after $16 \mathrm{~d}$, it reaches $16 \mathrm{~cm} \cdot \mathrm{s}^{-1}$ at the surface and $10 \mathrm{~cm} \cdot \mathrm{s}^{-1}$ at the 
bottom. Most of these differences can be explained by the presence of a strong current specified orthogonaly to the bottom topography in Experiment INT. After only a few hours, this current separates into two branches: one reaching the shelf through the canyon of Marseille figurd $\square$ d) and the other one going east below the NC and having a signature on the surface circulation (figure $1 /$ d). This latest branch reduced the vertical extend and the strength of the $\mathrm{NC}$ and increased with time between 200 and $500 \mathrm{~m}$ depth, slowly leading to a strong 'counter LPC current' that is physically inconsistent with observations in the region and never present in the regional scale circulation. Eigure $\mathrm{Mb}$ also shows a translation of the density front of about $10 \mathrm{~km}$ towards the south (tongue of light water along the eastern boundary). This tongue is not present when only the geostrophic current is used as a constraint in the analysis of the initial field, indicating the role of the truncation error in such a displacement in addition to the role of the boundary conditions. However, it cannot be concluded that the position of the density front in Experiment $A N A$ is more accurate than in Experiment $I N T$.

\subsection{Incoming/outgoing transport through the shelf break}

The incoming/outgoing total transport through the shelf during the first $400 \mathrm{~h}$ has been computed for both Experiments INT and ANA (the 'shelf' has been limited to the grid points north to the island of Le Planier; figure ). As a consequence of the transient processes which follow the initialization, the total transport in Experiment $I N T$ is greatly perturbed during the first $2 \mathrm{~d}$ of the experiment. On a longer time scale, two periods can be observed. When the south-east wind is blowing (after $150 \mathrm{~h}$ ), the incoming total transport first reached a maximum with $6 \times 10^{4}$ to $8 \times 10^{4} \mathrm{~m}^{3} \cdot \mathrm{s}^{-1}$. The rather low values of the total transport are a consequence of the fact that only part of the NC current is entering the modelling domain, the rest being located offshore. This maximum can be explained by two main mechanisms. The Ekman transport is towards the north in the surface layer and the NC sticks to the coast upstream, and enters the shelf by the different canyons figure 5 already shows an important incoming branch inside the canyon of Marseille). After day 10 and the arrival of the northern wind, the incoming total transport decreases to $3 \times 10^{4} \mathrm{~m}^{3} \cdot \mathrm{s}^{-1}$ in the modelling domain. A zonal section across the shelf break shows that the incoming branches of the LPC have totally disappeared and that the Ekman transport is now reversed (not shown). Thus, the response of the NC to the atmospheric forcing takes place on the order of the day and these rapid changes in the regional scale forcing affect at least all the eastern part of the Gulf of Lions. This confirms the observations made by Conan and Millot (1995) and leads to the conclusion that the $\mathrm{NC}$ displacements must be studied on a daily to weekly basis. In the region of Marseille, a strong correlation between the position of the core of the $\mathrm{NC}$ with the wind forcing is thus confirmed.

On a longer time scale, the comparison of the incoming total transports in Experiments INT and ANA also shows that they differ by more than $10 \%$ for about $60 \mathrm{~h}$, before converging towards similar values as soon as atmospheric forcing decreases. When the atmospheric forcing becomes important, the differences can still reach $7 \%$ after $300 \mathrm{~h}$, and the response to the wind bursts is in that case slightly out of phase.

\subsection{Sensitivity experiments}

The results presented so far for Experiments INT and $A N A$ show in particular large differences in the external mode solutions during the first hours of simulation. These results are however very dependent on the diffusion scheme that is implemented and it is very often believed that a smooth solution (in terms of external gravity waves for instance) can be obtained by increasing the model diffusion coefficient to unrealistic values during the adjustment period. We show here that in certain conditions such a procedure can lead to serious inaccuracies.

The same exact experiments are carried out but a centred scheme for advection with an horizontal diffusion equal to $80 \mathrm{~m}^{2} \cdot \mathrm{s}^{-1}$ instead of the upstream advective scheme (indeed more diffusive but with no additional diffusion) is used in the temperature and salinity equation. In such a case, we can show that the trajectories of Experiments INT and ANA are much closer than they were in the first twin experiments. Indeed, due to the 'over smoothing' of the circulation the current differences between Experiments INT and ANA is everywhere lower than $0.8 \mathrm{~cm} \cdot \mathrm{s}^{-1}$. As a consequence, an increase of the horizontal diffusion can obviously be seen as an efficient way to reduce the amplitude of the initial transient processes by damping quickly the gravity waves. However, foure 12 shows that the high resolution circulation obtained by increasing the 
(a)

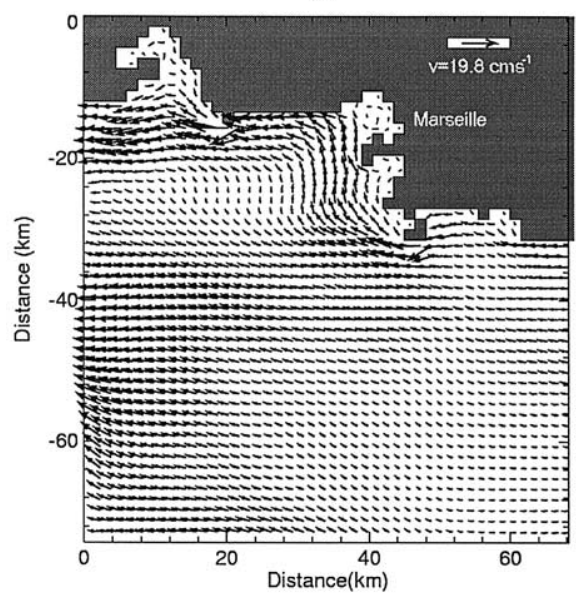

Min=0.00 Max=19.8 $\mathrm{t}=144.00 \mathrm{~h}$ (b)

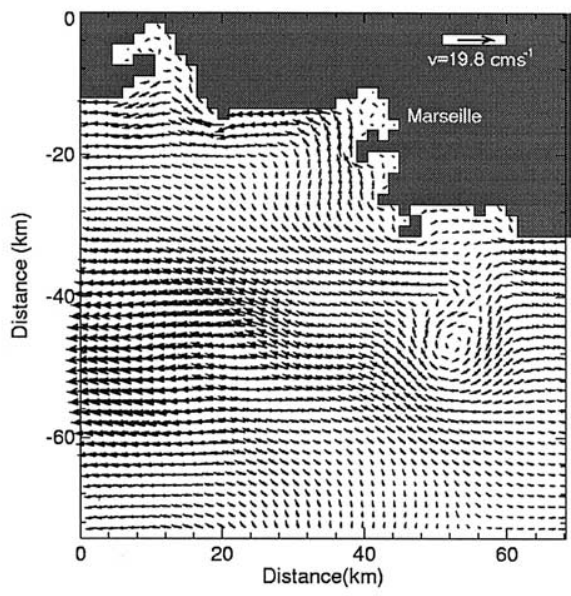

$M i n=0.00$ Max $=17.2 t=144.00 h$
Figure 12. Comparison of the high resolution circulation after $6 \mathrm{~d}$ in Experiment ANA: (a) with an upstream advective scheme and no additional diffusion, (b) with a centred advective scheme and additional diffusion. diffusion is somehow different from the corresponding one obtained with less horizontal diffusion. Indeed, in Ggure $12 b$, the coastal jet is larger and weaker and an anticyclonic circulation appeared in the canyon of Cassis. Thus, the comparison of Goure $12 a$ and $b$ shows that an important part of the processes that govern the interaction of the LPC with the shelf of the Gulf of Lions has been filtered out. In such a case the high resolution model does not provide much more information about the local circulation than the regional scale model does.

\section{DISCUSSION AND CONCLUSION}

We have shown in this paper the importance of a comprehensive modelling of the shelf break in the study of continental shelf high resolution circulation. The interaction of the $\mathrm{NC}$ with the south-eastern part of the shelf of the Gulf of Lions has been considered and the quick response of the $\mathrm{NC}$ to the atmospheric forcing has been confirmed. The largest part of the exchanges was found to be concentrated through the numerous canyons spread in this region over the shelf break (canyon of Cassis, canyon of Marseille, ...). As a consequence, the specification of general circulation can only be based on a circulation model or on observations that deal with such processes. As an illustration, the modelling of the region of Marseille without any consistent knowledge of the position of the NC in the Ligurian basin has been shown to be pointless.
The importance of the analysis of the initial and forcing regional scale field has also been acknowledged and has been recognized as a solution to the problem of the initialization and forcing of a high resolution model. For the first time, a 3D variational initialization technique based on the high resolution tangent model is used to adjust the regional scale fields to high resolution constraints such as the physics of the model itself or its bottom topography. The comparison of this method of analysis with a crude interpolation of the regional scale fields showed the importance of both the initialization and the open boundary forcing on the short and longer time scale circulations. This makes the ocean initialization problem rather different from its atmospheric counterpart. Indeed, the initialization of a high resolution coastal model cannot be limited to the removal of the numerical high frequency transients that inevitably follow the initialization. We have shown indeed that these transients also had crucial consequences on the pressure field. In the shallow regions, the smoothing of the pressure field during the initialization spin up can for instance reduce the coastal jet and its related dynamics. The analysis of the initialization field is also a way to reduce the amplitude of some of the largest bias of the Sigma-coordinate coastal model such as its horizontal pressure gradient truncation error (Auclair et al. 2000b. The analysis of the open boundary forcing was found to be the third important component of the inverse method. We have shown indeed that the crude specification in Experiment INT of the regional scale fields along the 
southern open boundary leads to a deep counter current eventually interacting with the NC.

The coastal ocean initialization problem thus most certainly includes all the problems of its atmospheric counterpart but cannot be limited to it. The coastal initialization problem is also more ticklish than in large-scale ocean modelling where the model can easily be spun up for long periods of time. So far very few studies have been dedicated to this problem for the coastal ocean, though we truly believe that it is a crucial prerequisite to the development of operational coastal oceanography.

\section{Acknowledgements}

This work was carried out in the framework of the French 'Programme atmosphère et océan à multi-échelles' (Patom) and of the MAST-III-ELOISE European Community Metro-Med Project. We acknowledge the support of the Epshom. The authors also gratefully thank L. Mortier (Ensta, Lodyc) for providing OPA output fields and S. Prieur (LA, Toulouse) for his technical support.

\section{Appendix}

The high resolution 'first guess' or 'background' field $x^{b}$ is obtained using a classical Gaussian interpolation. Both the external and internal mode variables are interpolated on the high resolution grid following:

$$
x_{i, j}^{b}=\frac{\sum_{(\alpha, \beta)} \exp \left(-\frac{r^{2}}{R^{2}}\right) y_{\alpha, \beta}^{d}}{\sum_{(\alpha, \beta)} \exp \left(-\frac{r^{2}}{R^{2}}\right)}
$$

$x_{i, j, k}^{b}=\frac{\sum_{(\alpha, \beta)} \exp \left(-\frac{r^{2}}{R^{2}}\right)\left[y_{\alpha, \beta, \gamma 1}^{d} * d+y_{\alpha, \beta, \gamma 2}^{d} *(1-d)\right]}{\sum_{(\alpha, \beta)} \exp \left(-\frac{r^{2}}{R^{2}}\right)}$

where $(i, j)$ is a point of the high resolution grid and $(\alpha, \beta)$ a point of the regional scale grid. The distance between the points $(i, j)$ and $(\alpha, \beta)$ is given by $r$ and $R$ is equal to $5 \mathrm{~km}$. The vertical distance between points $(i, j, k)$ and $(\alpha, \beta, \gamma)$ is given by $d$ and the vertical interpolation is linear, $\gamma_{1}$ and $\gamma_{2}$ satisfying $z\left(\gamma_{2}\right) \leq z(k) \leq z\left(\gamma_{1}\right)$.

\section{REFERENCES}

Auclair, F., 1999. Modélisation Océanographique Côtière: initialisation et forçage. Ph.D. thesis, University of Toulouse III.

Auclair, F., Casitas, S., Marsaleix, P., 2000a. Application of an inverse method to coastal modeling. J. Atmos. Oceanic Technol. 17, 1368-1391.

Auclair, F., Marsaleix, P., Estournel, C., 2000b. Sigma coordinate pressure gradient errors: evaluation and reduction by an inverse method. J. Atmos. Ocean Technol. 17, 1348-1367.

Alberola, C., Millot, C., Font, J., 1995. On the seasonal and mesoscale variabilities of the Northern Current during the PRIMO-0 experiment in the western Mediterranean sea. Oceanol. Acta 18, 163-192.

Arakawa, A., Lamb, V.R., 1977. Computational design of the basic dynamical processes of the UCLA general circulation model, Method. Comput. Phys. 17, 173-265.

Astraldi, M., Gasparini, G.P., 1992. Seasonal characteristics of the circulation in the western Mediterranean basin and their relationships with the atmospheric-climatic conditions. J. Geosphys. Res. 97, 9531-9540.

Beckmann, A., 1998. The representation of bottom boundary malyer processes in numerical ocean circulation models. In: Chassignet, E.P., Verron, J. (Eds.), Ocean Modeling and Parameterization, Nato Science Series, vol. 516.

Béthoux, J.P., Prieur, L., Bong, J.H., 1988. Le courant Ligure au large de Nice. In: Minas, H.J., Nival, P. (Eds.), Océanographie pélagique méditerranéenne, Oceanol. Acta No. Sp. 9, pp. 59-67.

Blumberg, A.F., Mellor, G.L., 1987. A description of a threedimensional coastal circulation model. In: Heaps, N.S. (Ed.), Three Dimensional Coastal Ocean Models, Coastal and Estuarine Sciences, vol. 4. American Geophysical Union, Washington, DC, pp. 1-16.

Bretherton, F.P., Davis, R.E., Fandry, C.B., 1976. A technique for objective analysis and design of oceanographic experiments applied to MODE-73. Deep-Sea Res. 23, 559-582.

Caraux, D., Austin, R.W., 1984. Multispectral satellite remote sensing of an oceanic cyclone in the northwestern Mediterranean. Int. J. Remote Sens. 5, 855-860.

Conan, P., Millot, C., 1995. Variability of the Northern Current off Marseilles, Western Mediterranean Sea from February to June 1992. Oceanol. Acta 18, 193-205.

Crépon, M., Boukthir, R.W., 1987. Effect of deep water formation on the circulation of the Ligurian Basin. Annal. Geophys. 5B, 43-48.

Crépon, M., Wald, L., Monget, J.M., 1982. Low-frequency waves in the Ligurian Sea during December. J. Phys. Oceanogr. 87, 595-600.

Durrieu de Madron, X., Nyffeler, F., Godet, C.H., 1990. Hydrographic structure and nepheloid spatial distribution in the Gulf of Lions continental margin. Cont. Shelf Res. 10, 915-929.

Estournel, C., Kondrachoff, V., Marsaleix, P., Vehil, R., 1997. The plume of the Rhone: numerical simulation and remote sensing. Cont. Shelf Res. 17, 899-924. 
Estournel, C., Broche, P., Marsaleix, P., Devenon, J.L., Auclair, F., Vehil, R., 2001. The Rhône river plume in unsteady conditions: numerical and experimental results. Estuar. Coast. Shelf Sci. 53, 25-38.

Gaspar, P., Grégoris, Y., Lefevre, J.M., 1990. A simple eddy kinetic energy model for simulations of the oceanic vertical mixing tests at station Papa and long-term upper ocean study site. J. Geophys. Res. 95, 179-193.

Grilli, F., Pinardi, N., 1998. The computation of Rossby radii of deformation for the Mediterranean sea. MTP News No. 6, March 1998.

Haney, R.L., 1991. On the pressure gradient force over steep topography in sigma coordinate ocean models. J. Phys. Oceanogr. 21, 610-619.

Herbaud, C., 1994. Étude de la circulation océanique en Méditerranée Occidentale. Thèse de doctorat de l'université Paris 6.

Herbaud, C., Mortier, L., Crépon, M., 1996. A Sensitivity Study of the General Circulation of the Western Mediterranean Sea. Part I: The
Response to Density Forcing through the Straits. J. Phys. Oceanogr. 26, 65-84.

Ide, K., Courtier, P., Ghil, M., Lorenc, A.C., 1997. Unified Notation for Data Assimilation: Operational, Sequential and Variational. J. Meteor. Soc. Jap. 75, 181-189.

Marsaleix, P., Estournel, C., Kondrachoff, V., Vehil, R., 1998. A numerical study of the formation of the Rhône River plume. J. Mar. Res. 14, 99-115.

Mellor, G.L., Ezer, T., Oey, L.Y., 1994. The pressure gradient conundrum of sigma coordinate ocean models. J. Atmos. Oceanic Technol. 11, 1126-1134.

Millot, C., 1991. Mesoscale and seasonal variabilities of the circulation in the western Mediterranean. Dyn. Atmos. Oceans 15, 179-214.

Orlanski, I., 1976. A simple boundary condition for unbounded hyperbolic flows. J. Comp. Phys. 21, 255-261.

Sasaki, U., 1960. An objective analysis for determining initial conditions for the primitive equations. Tech. Rep 208, Department of Oceaonography and Meteorology, A \& M College of Texas. 